\title{
A Comparative Study Between Clomiphene Citrate and Tamoxifen for induction of Ovulation in Women Complaining of Polycystic Ovary Syndrome
}

\author{
Ramzy Bahnasy Yehia ${ }^{1}$ MBBCh; Abdallah Khalil Ahmed ${ }^{1}$ MD; Samir Khamis Galal ${ }^{1}$ MD.
}

\author{
* Corresponding Author: \\ Ramzy Bahnasy Yehia \\ Ramzybahnasy@yahoo.com
}

Received for publication June 20 , 2020; Accepted August 29, 2020 Published online August 30, 2020.

Copyright 2020 The Authors published by Al-Azhar University, Faculty of Medicine, Cairo, Egypt. All rights reserved. This an open-access article distributed under the legal terms, where it is permissible to download and share the work provided it is properly cited. The work cannot be changed in any way or used commercially.

doi: 10.21608/aimj.2020.30445.1229

${ }^{l}$ Obstetrics and Gynaecology Department, Faculty of Medicine, Al Azhar University, Cairo, Egypt.

\begin{abstract}
Background: PCOS is the most common endocrine disorder among women between the ages of 18 and 44 . It affects approximately $2 \%$ to $20 \%$ of this age group depending on how it is defined. PCOS is due to a combination of genetic and environmental factors.

Aim of work: The study aimed to compare the efficacy of Clomiphene citrate and Tamoxifen in induction of ovulation in women with polycystic ovary syndrome.

Patient and Methods: This clinical trial study was conducted at AlHusien Hospital from June 2019 to December 2019 after approval of the research ethics committee, on 100 patients with P.C.O. The participants were recruited from women attending the outpatient infertility clinic of AlHusien Hospital. Patients are classified randomly into 2 groups: Group A: 50 patients (clomiphene Group). Group B: 50 patients (tamoxifene Group).

Results: Ovulation rate was significantly better under tamoxifen therapy. Pregnancy rate was significantly better under tamoxifen therapy. Number of stimulated follicles was not significantly different between the two drugs. Endometrial thickness was significantly better under tamoxifen therapy "both preovulatory and midluteal". Endometrial perfusion volume (EV), Vascularization index (VI), and Vascularization flow index (VFI) were significantly better under tamoxifen therapy. Adverse effects with the two drugs were non-significant. Endometrial perfusion indices were significantly better in pregnant versus non-pregnant cases.

Conclusion: Tamoxifen can give similar or even better results than clomiphene citrate in induction of ovulation in women with PCOS. Each of them can be used as a first line option for induction of ovulation in women with PCOS "in selected cases".
\end{abstract}

Keywords: : Clomiphene Citrate; Tamoxifen; Polycystic Ovary Syndrome

Disclosure: The authors have no financial interest to declare in relation to the content of this article. The Article Processing Charge was paid for by the authors.

Authorship: All authors have a substantial contribution to the article.

\section{INTRODUCTION}

Women with PCOS tend to have central obesity, but studies are conflicting as to whether visceral and subcutaneous abdominal fat is increased, unchanged, or decreased in women with PCOS relative to reproductively normal women with the same body mass index. ${ }^{1}$ Two of the following three criteria are required for diagnosis of PCOS: oligomenorrhea or amenorrhea, clinical or biochemical signs of hyperandrogenism, or both; polycystic ovaries as seen on ultrasound scanning. ${ }^{2}$ Several methods have been effective for ovulation induction and fertility treatment in women with PCOS: Weight loss, exercise and lifestyle modifications. Anti-estrogens (CC and TMX). Femara or letrozole and other aromatase inhibitors. Metformin and gonadotropins. ${ }^{3}$
Clomiphene citrate (CC) is a non-steroidal SERM, has both estrogen agonist and antagonist properties. It binds to estrogen receptors primarily in the hypothalamus, which interrupts the negative feedback of the increasing estrogen level and results in continued production of $\mathrm{FSH}$, which stimulates follicular growth and maturation. ${ }^{4}$ Its antiestrogenic effect causes long standing estrogen receptor depletion due to its long half-life (2weeks), so it has adverse effects on the quality and quantity of cervical mucus and negative impact on endometrial development causing its significant thinning, implantation failure and decreased blood flow during the peri-implantation stage. ${ }^{5}$

CC resistance affects approximately $15 \%$ to $40 \%$ of women with PCOS, perhaps because of antiestrogenic 
effects of $\mathrm{CC}$ to the endometrium and cervical mucus, or because of luteinizing hormone hypersecretion. CC resistance is defined as a lack of ovulation after 6 cycles of $\mathrm{CC}$, tamoxifen is as effective as $\mathrm{CC}$ in inducing ovulation in anovulatory women with normal prolactin levels, but it has a much lesser antiestrogenic effect on the endometrium, cervical mucus, and granulosa cells. ${ }^{6}$ Tamoxifen is a nonsteroidal SERM, commonly used today as an adjuvant therapy in treatment of breast cancer. It acts primarily by binding estrogen receptors at the hypothalamus, this competitive inhibition results in a perceived drop in endogenous estrogen levels, eventually leading to increased gonadotrophin secretion and subsequent induction of ovulation. ${ }^{5}$ It acts as an agonist on estrogen receptors of endometrium and vaginal mucosa, its half life is short (5-7 days) leading to favorable cervical mucus, better endometrial thickness, and maybe better endometrial blood flow. ${ }^{7}$

The study aimed to compare the efficacy of Clomiphene citrate and Tamoxifen in induction of ovulation in women with polycystic ovary syndrome.

\section{PATIENT AND METHODS}

This clinical trial study was conducted at Al-Husien Hospital from June 2019 to December 2019 after approval of the research ethics committee, on 100 patients with P.C.O. The participants were recruited from women attending the outpatient infertility clinic of Al-Husien Hospital.

Inclusion criteria: Age. Primary infertility. Body mass index (BMI) between 25 and $35 \mathrm{Kg} / \mathrm{m} \mathrm{2}$. Polycystic ovary syndrome (using ESHRE/ASRM criteria).

Exclusion criteria: Secondary infertility. Patients with BMI under 25 or over $35 \mathrm{Kg} / \mathrm{m} 2$. Hyper or hypothyroidism, or hyperprolactinemia. Current or previous (within the last six months) use of oral contraceptives, glucocorticoids, antiandrogens, antidiabetic and anti-obesity drugs, or other hormonal drugs. Intention to start a diet or a specific program of physical activity. Organic pelvic diseases. Tubal or male factor infertility. Interval of earlier treatment with any of the fertility drugs of less than 6 months before being recruited in the study. Clomiphene citrate. Tamoxifen. HCG injection.

Participants that seem to be fulfilling all the inclusion and exclusion criteria were recruited, then an informed written consent was taken from every participant before starting the study. Participants not fulfilling all inclusion and exclusion criteria were dropped from the study and not considered as part of the calculated sample size.

All participants were subjected to the following: (i) History: A careful and detailed history was taken including name, age, occupation, residence, socioeconomic status, special habits of medical importance, history suggestive of PCOS (infertility, hirsutism, obesity and anovulation), menstrual history, obstetric history, sexual history, family history, past history of medical disorders, history of medications or allergy and surgical history "Previous surgery or Previous laparotomies". (ii) Examination: (A) General examination: Maternal body weight, height and BMI. Presence of petechiae or ecchymosis of the skin to exclude presence of coagulation defect or blood disease. Cardiac and chest examination. Vital data. Presence of pallor or jaundice. Breast examination. (B) Pelvi-abdominal examination: Uterine or adnexal masses. Scar of previous operations. (iii) Investigations: Hormonal profile on day 2-3 of the cycle. Semen analysis to rule out male factor. Hysterosalpingography (HSG) to confirm tubal patency. Transvaginal ultrasound to detect anatomical uterine or adnexal abnormalities.

Patients are classified randomly into 2 groups: Group A: 50 patients ( clomiphene Group). Group B: 50 patients ( tamoxifene Group).

Start treatment from 2nd day of cycle by: Group A: 1 tab clomiphene $50 \mathrm{mg}$ Twice daily For Five Days . Group B: 1 tab tamoxifene $10 \mathrm{mg}$ Twice daily For Five Days.

Primary outcome: Rate of ovulation.

Secondary outcome: Endometrial perfusion by using 3D- power Doppler (GE Medical system volouson E6, 5-7 MHz) in the mid luteal day of the cycle to assess endometrial receptivity. Endometrial thickness and quality in the pre-ovulatory and mid luteal period. Number of growing follicles detected by transvaginal ultrasound. Patient compliance. Adverse effects: such as headache, nausea, vomiting, breast tenderness, blurred vision, and ovarian enlargement or hyperstimulation.

Statistical Methods: Data were fed to the computer and analyzed using IBM SPSS software package version 20.0. (Armonk, NY: IBM Corp). The Kolmogorov-Smirnov test was used to verify the normality of distribution Quantitative data were described using range (minimum and maximum), mean, standard deviation, median and interquartile range (IQR). Significance of the obtained results was judged at the $5 \%$ level. P-value $<0.05$ was considered statistically significant. 
RESULTS

\begin{tabular}{|c|c|c|c|c|c|c|c|}
\hline & \multicolumn{4}{|c|}{ Group } & \multirow{3}{*}{$\begin{array}{c}\text { Chi- square } \\
\text { test }\end{array}$} & \multirow{3}{*}{ P-value } \\
\hline & & \multicolumn{2}{|c|}{$\begin{array}{l}\text { Clomiphene Citrate }(\mathrm{n}= \\
50)\end{array}$} & \multicolumn{2}{|c|}{$\begin{array}{l}\text { Tamoxifen } \\
(\mathrm{n}=50)\end{array}$} & & \\
\hline & & No. & $\%$ & No. & $\%$ & & \\
\hline \multirow[t]{2}{*}{ Ovulation } & No & 27 & 54.0 & 19 & 38.0 & \multirow[t]{2}{*}{2.576} & \multirow[t]{2}{*}{0.108} \\
\hline & Yes & 23 & 46.0 & 31 & 62.0 & & \\
\hline
\end{tabular}

Table 1: Comparison between group I (Clomiphene Citrate) and II (Tamoxifen) as regard Ovulation rate (Chisquare test Data presented as number (percentage)).

\begin{tabular}{|l|c|c|c|}
\hline & $\begin{array}{c}\text { Clomiphene Citrate } \\
(\mathrm{n}=23)\end{array}$ & $\begin{array}{c}\text { Tamoxifen } \\
(\mathrm{n}=31)\end{array}$ & P-Value \\
\hline No_of_follicles & $3.044 \pm 0.638$ & $3.21 \pm 0.733$ & 0.389 \\
\hline $\begin{array}{l}\text { Diameter_of_Follicle } \\
(\mathrm{mm})\end{array}$ & $20.19 \pm 1.45$ & $20.78 \pm 1.64$ & 0.175 \\
\hline
\end{tabular}

Table 2: Comparison between group I (Clomiphene Citrate) and II (Tamoxifen) as regard No. of follicles $\geq 18 \mathrm{~mm}$ at day of HCG injection and mean diameter of follicles (Independent sample t-test Data presented as mean \pm standard deviation (range)).

\begin{tabular}{|c|c|c|c|c|}
\hline Tri-laminar Endometrium & $\begin{array}{c}\text { Clomiphene Citrate } \\
(\mathrm{n}=23)\end{array}$ & $\begin{array}{c}\text { Tamoxifen } \\
\text { Chi- square test } \\
(\mathrm{n}=31)\end{array}$ & P-Value \\
\hline Yes & $11(47.8 \%)$ & $14(45.2 \%)$ & \multirow{2}{*}{0.038} & 0.846 \\
\hline No & $12(52.5 \%)$ & $17(54.3 \%)$ & & \\
\hline
\end{tabular}

Table 3: Comparison between group I (Clomiphene Citrate) and II (Tamoxifen) as regard Presence of Tri- laminar endometrium (preovulatory) (Chi-square test Data presented as number (percentage)).

\begin{tabular}{|l|c|c|c|}
\hline & $\begin{array}{c}\text { Clomiphene Citrate } \\
(\mathrm{n}=23)\end{array}$ & $\begin{array}{c}\text { Tamoxifen } \\
(\mathrm{n}=31)\end{array}$ & P-Value \\
\hline Endometrial perfusion & $\begin{array}{c}5.3 \pm 2.4 \\
(1.37-9.12)\end{array}$ & $\begin{array}{c}6.4 \pm 2.27 \\
(1.67-9.65)\end{array}$ & 0.092 \\
\hline volume (ml) & $\begin{array}{c}1.11 \pm 1.03 \\
(0-3.07)\end{array}$ & $\begin{array}{c}1.55 \pm 0.87 \\
(0-3.07)\end{array}$ & 0.095 \\
\hline VI $(\%)$ & $\begin{array}{c}18.86 \pm 9.93 \\
(0.1-27.045)\end{array}$ & $\begin{array}{c}21.52 \pm 7.01 \\
(0.1-28.856)\end{array}$ & 0.253 \\
\hline FFI & $\begin{array}{c}0.186 \pm 0.087 \\
(0.049-0.306)\end{array}$ & $\begin{array}{c}0.235 \pm 0.06 \\
(0.065-0.303)\end{array}$ & $<0.001^{*}$ \\
\hline
\end{tabular}

Table 4: Comparison between group I (Clomiphene Citrate) and II (Tamoxifen) as regard Endometrial Perfusion volume, VI, FI, VFI (Independent sample t-test

Data presented as mean \pm standard deviation (range)).

\begin{tabular}{|c|c|c|c|}
\hline & $\begin{array}{l}\text { Clomiphene Citrate } \\
(\mathrm{n}=23)\end{array}$ & $\begin{array}{c}\text { Tamoxifen } \\
(\mathrm{n}=31)\end{array}$ & P-Value \\
\hline Progesterone (ng/ml) & $\begin{array}{c}10.87 \pm 4.9 \\
(4-20)\end{array}$ & $\begin{array}{c}13.18 \pm 4.8 \\
(4-20)\end{array}$ & 0.089 \\
\hline
\end{tabular}

Table 5: Comparison between group I (Clomiphene Citrate) and II (Tamoxifen) as regard midluteal serum Progesterone (Independent sample t-test

Data presented as mean \pm standard deviation (range)). 


\section{DISCUSSION}

Anti-estrogens are effective for induction of ovulation in women with PCOS, this study was done to compare the efficacy of induction of ovulation in women with PCOS with Clomiphene citrate "CC" versus Tamoxifen "TMX". The study was conducted during the period from June 2019 to December 2019 at AlHusien Hospital - Infertility Clinic. 100 cases randomly allocated into two groups "50 participants for each group", and received either $100 \mathrm{mg} \mathrm{CC}$ and placebo of TMX, or $20 \mathrm{mg}$ TMX and placebo of CC, from day 3 to day 7 of the cycle, after progesterone induced withdrawal bleeding in women with abnormal menstrual history.

The absence of a dominant follicle (DF $\geq 18 \mathrm{~mm}$ ) by Day 25 was considered as a failed induction or anovulation. The groups were matched according to type of anovulation "PCOS", type of infertility "primary infertility", and BMI "between 25 and 35 $\mathrm{Kg} / \mathrm{m} 2 "$. Mean BMI for CC group $( \pm \mathrm{SD}) 27.95 \pm$ $0.806 \mathrm{~kg} / \mathrm{m}^{2}$, range $\left(25.6-30 \mathrm{~kg} / \mathrm{m}^{2}\right)$, mean BMI for TMX group $( \pm \mathrm{SD}) 28.15 \pm 0.643 \mathrm{~kg} / \mathrm{m}^{2}$, range $(26-$ $\left.30 \mathrm{~kg} / \mathrm{m}^{2}\right)$. Mean age for CC group $( \pm$ SD) $26.88 \pm$ 2.65 years, range (21 - 32 years), mean age for TMX group ( \pm SD) $26.87 \pm 2.51$ years, range ( 22 - 32 years).

This study is in disagreement with Pant 8 a prospective, randomized, open-label, single centre study comparing efficacy of CC and TMX for induction of ovulation among women with anovulatory infertility where 200 anovulatory women "failed to develop dominant follicle 18-22 mm for consecutive three cycles" aging 20- 40 years old and with only primary infertility allocated into two groups; 100 women for CC, and 100 women for TMX. CC was given $50 \mathrm{mg} /$ day in first cycle second day of cycle for 5 days, if there was no adequate size follicular development the dose was increased in next cycle, maximum dose $150 \mathrm{mg} /$ day, $\mathrm{CC}$ was repeated maximum for 6 cycles. TMX was given in the second group $20-60 \mathrm{mg} /$ day from the same day of menstrual cycle and same duration as $\mathrm{CC}$.

Pant ${ }^{8}$ reported ovulation rate $44 \%$ for CC $100 \mathrm{mg}$, and $21 \%$ for TMX $20 \mathrm{mg}$, but there was no statistical significant difference between the two groups, his evaluation for ovulation was according to the development of adequate follicular size (18-22 mm), not according to signs of ovulation clinically, radiologically and biochemically after giving HCG. Pant ${ }^{8}$ repeated cycle stimulation with CC and TMX "up to 6 cycles" with different doses of both drugs.

Brown et al. ${ }^{9}$ a Cochrane Review included 15 randomized controlled trials (RCTs); CC (50 to 250 $\mathrm{mg}$ ) versus placebo: analysis of the three trials comparing CC with placebo shows that CC improves ovulation and pregnancy rates. Analysis for ovulation rate (per woman) showed a benefit of CC compared with placebo ( 3 trials, 133 participants; fixed OR 7.47, $95 \%$ CI 3.24 to $17.23 ; \mathrm{P}<0.00001)$.

Some studies reported higher CC ovulation rate than the result in this study:

Roy et al. ${ }^{10}$ a prospective randomized single center trial comparing the efficacy of letrozole and $\mathrm{CC}$ in induction of ovulation in women with PCOS where 204 women aging 20-35 years divided into two groups 98 cases (294 cycles) received 2.5-5 mg of letrozole; 106 cases ( 318 cycles) received 50-100 $\mathrm{mg}$ of $\mathrm{CC}$, the treatment continued for three cycles in both the groups. Of 106 cases in CC group, 69 cases had been given $50 \mathrm{mg} \mathrm{CC}$ in all three study cycles, 18 cases were given $50 \mathrm{mg} \mathrm{CC}$ in two cycles and stepped up to $100 \mathrm{mg}$ in the third cycle, and 19 cases received $50 \mathrm{mg}$ $\mathrm{CC}$ in first cycle and $100 \mathrm{mg}$ for second and third cycle with reported cumulative ovulatory rate of $67.9 \%$.

Dhaliwal et al. ${ }^{7}$ trial included 160 PCOS women, where TMX $40 \mathrm{mg}$ (20 mg twice a day) was given from day 5-9 of the cycle in the first cycle. If ovulation did not occur, the dose of TMX was increased to 80 $\mathrm{mg}$ (40 mg twice a day). Out of 160 women $70 \mathrm{had}$ already received treatment with $\mathrm{CC}$ and were considered as CC failures. Out of the 70 women, 50 required $80 \mathrm{mg}$ of TMX, CC failure was defined as failure to ovulate with $150 \mathrm{mg}$ of CC. Out of 160 women 125 ovulated and 55 of them became pregnant. The ovulation rate achieved in this study was $78.1 \%$ and out of a total of 360 treatment cycles, $69.2 \%$ were ovulatory.

These results are slight higher than the results in this study due to a higher TMX dose, repeated cycle stimulation, higher doses for previous CC failures, induction of ovulation from day 5-9 of the cycle and lower diameter of dominant follicle ( $\mathrm{DF} \geq 17 \mathrm{~mm})$.

This study shows a statistically significant difference between CC and TMX as regard to pregnancy rate which was significantly better in TMX group $26.5 \%$ (74/279 cycles) than in CC group $15.2 \%(42 / 276$ cycles) $(\mathrm{p}<0.01)$.

This study is in disagreement with Badawy and Gibreal 2 which reported better pregnancy rate in the CC group (18.7\%) "35/187 cycles" than in the TMX group $(10.8 \%)$ "20/184 cycles" with a significant difference between two groups in favors of clomiphene $(\mathrm{p}<0.01)$, possibly also due to lower age and BMI measures in CC group, although not statistically significant.

This study reported number of cases reaching at least single dominant follicle " $\geq 18 \mathrm{~mm}$ in days $10-25$ of the cycle" of $44.7 \%$ in CC group, and $59.4 \%$ in TMX group, without any statistical significant difference between the two groups as regard to number or diameter of growing follicles which were even better 
in TMX group than in CC group. Mean No. of stimulated follicles " $\geq 18 \mathrm{~mm}$ in days 10 - 25 of the cycle" for CC $( \pm$ SD) $3.044 \pm 0.638$, range $(2-4)$, mean No. for TMX $( \pm \mathrm{SD}) 3.21 \pm 0.733$, range $(2-5)$. Mean diameter of stimulated follicles for CC $( \pm \mathrm{SD}) \pm$ $1.45 \mathrm{~mm}$, range $(18-25 \mathrm{~mm})$, mean diameter for TMX ( \pm SD) $20.78 \pm 1.64 \mathrm{~mm}$, range (18 - $25 \mathrm{~mm})$.

This study is in disagreement with Badawy and Gibreal $^{2}$ which reported that the number of stimulated follicles reaching $\geq 18 \mathrm{~mm}$ diameter was significantly more in the CC group compared to TMX stimulated group (2.1 $\mathrm{SD} \pm 0.1$ vs. $1.1 \mathrm{SD} \pm 0.7, \mathrm{p}<0.0001)$.

This study is in agreement with Badawy and Gibreal ${ }^{2}$ who reported a significantly thicker endometrium "preovulatory" in TMX group in comparison with CC group $(10.1 \pm 0.1 \mathrm{~mm}$ vs. $9.3 \pm 0.4 \mathrm{~mm}, \mathrm{p}<0.0001)$, although these values are higher than the values reported in this study and without referral to endometrial pattern.

Pant ${ }^{8}$ reported that endometrial thickness was 8 -13 $\mathrm{mm}$ in $90.1 \%$ cases, and $<8 \mathrm{~mm}$ in $9.9 \%$ cases when $\mathrm{CC}$ was given $100 \mathrm{mg}$, and that endometrial thickness was $8-13 \mathrm{~mm}$ in $88 \%$ cases, and $<8 \mathrm{~mm}$ in $12 \%$ cases when TMX was given $20 \mathrm{mg}$.

Roy et al. ${ }^{10}$ reported mean midcycle "preovulatory" trilaminar layer of endometrial thickness in CC group $( \pm \mathrm{SD}) 6.3 \pm 1.1 \mathrm{~mm}$, although confined to as trilaminar.

Dhaliwal et al. ${ }^{7}$ reported that endometrial thickness "preovulatory" was more than $8 \mathrm{~mm}$ in $60 \%$ and 6-8 $\mathrm{mm}$ in $30 \%$ and more than $10 \mathrm{~mm}$ in $10 \%$ of women, who received TMX for induction of ovulation. Close to the reported results in this study mean preovulatory endometrial thickness for TMX group $( \pm$ SD) $7.9 \pm$ $2.25 \mathrm{~mm}$, range (4-11 mm).

As regard 3D power doppler endometrial perfusion indices for assessment of endometrial receptivity, this study shows a highly statistically significant difference between the two groups as regard VFI which was better in TMX group $(\mathrm{P}<0.01)$. There is also a statistically significant difference between the two groups as regard endometrial volume and VI in favors of TMX $(\mathrm{P}<0.05)$.

FI although better in TMX group, there is no statistical significant difference between CC group and TMX group. Mean Endometrial Perfusion Volume "by 3D power doppler" for CC group $( \pm \mathrm{SD}) 5.3 \pm 2.4 \mathrm{ml}$, range (1.37 -9.12 ml), mean Volume for TMX group ( $\pm \mathrm{SD}) 6.4 \pm 2.27 \mathrm{ml}$, range $(1.67-9.65 \mathrm{ml})$.

Mean Vascularization Index (VI) "by 3D power doppler" for CC group $( \pm \mathrm{SD}) 1.11 \pm 1.03 \%$, range $(0$ $-3.07 \%)$, mean VI for TMX group $( \pm$ SD) $1.55 \pm 0.87$ $\%$, range $(0-3.07 \%)$. Mean Flow Index $(\mathrm{FI})$ for CC group $( \pm$ SD) $18.86 \pm 9.93$, range $(0.1-27.045)$, mean FI for TMX group $( \pm$ SD) $21.52 \pm 7.01$, range $(0.1-$ 28.856). Mean Vascularization Flow Index (VFI) for CC group ( \pm SD) $0.186 \pm 0.087$, range $(0.049-0.306)$, mean VFI for TMX group $( \pm$ SD) $0.235 \pm 0.06$, range (0.065 - 0.303).

This study is also in agreement with Mercé et al. ${ }^{\mathbf{1 1}}$ prospective, nonrandomized, single centre, clinical study done to detect if the endometrial parameters by three- dimensional ultrasound and power Doppler angiography related to IVF-ET outcome, included 80 infertile women underwent a first IVF/ICSI cycle, endometrial 3D US-PDA evaluated by VOCAL software (plane $\mathrm{C}$ and 9 degrees of rotational steps) was done. The main outcome measures were endometrial pattern, endometrial thickness, endometrial volume, and PDA indexes of vascularization index (VI), flow index (FI), and vascularization flow index (VFI) measured on the day of HCG administration.

\section{CONCLUSION}

Tamoxifen can give similar or even better results than clomiphene citrate in induction of ovulation in women with PCOS. Each of them can be used as a first line option for induction of ovulation in women with PCOS "in selected cases". 3D Power Doppler endometrial perfusion is a good method for assessment of endometrial receptivity in cases of induction of ovulation.

\section{REFERENCES}

1. Sam S. Adiposity and metabolic dysfunction in polycystic ovary syndrome". Horm Mol Biol Clin Investig. 2015; 21 (2): 107-16.

2. Badawy A and Gibreal A. Clomiphene citrate versus tamoxifen for ovulation induction in women with PCOS: a prospective randomized trial. Eur J Obstet Gynaecol Reprod Biol. 2011; 159: $151-4$.

3. Vause TD, Cheung AP, Sierra S, Claman P, Graham J, et al. Ovulation induction in polycystic ovary syndrome. JOGC. 2010; 32(5): 495-502.

4. Seyedoshohadaei F, Zandvakily $\mathrm{F}$ and Shahgeibi S. Comparison of the effectiveness of clomiphene citrate, tamoxifen and letrozole in ovulation induction in infertility due to isolated unovulation. Iran J Reprod Med. 2012; 10(6): 531-6.

5. Steiner AZ, Terplan $M$ and Paulson RJ. Comparison of clomiphene citrate and tamoxifen for ovulation induction. Hum Reprod. 2005; 20 : 1511-5.

6. Zakherah MS, Nasr A, El Sama AM, Shaaban OM and Shahin AY. Clomiphene citrate plus tamoxifen versus laparoscopic ovarian drilling in women with clomiphene-resistant polycystic ovary syndrome. Int J Gynaecol Obstet. 2010; 108: 240-43. 
7. Dhaliwal LK, Suri V, Gupta KR and Sahdev S. Tamoxifen: An alternative to clomiphene in women with polycystic ovary syndrome. J Hum Reprod Sci. 2011; 4(2): 76-9.

8. Pant PR. Comparsion of efficacy of clomiphene citrate and tamoxifen for induction of ovulation among women with anovulatory infertility. Med Inn. 2013; 2(1): 68- 71 .

9. Brown J, Farquhar C, Beck J, Boothroyd C and Hughes E. Clomiphene and anti-oestrogens for ovulation induction in PCOS. Cochrane Database Syst Rev. 2009; 4: CD002249.

10. Roy KK, Baruah J, Singla S, Sharma JB, Singh N, et al. A prospective randomized trial comparing the efficacy of Letrozole and Clomiphene citrate in induction of ovulation in polycystic ovarian syndrome. J Hum Reprod Sci., 2012; 5(1): 20-5.

11. Mercé LT, Barco MJ, Bau S and Troyano J. Are endometrial parameters by three-dimensional ultrasound and power Doppler angiography related to in vitro fertilization/embryo transfer outcome?. Fertil Steril. 2008; 89(1): 111-7. 